\title{
Natural language processing of radiology reports for identification of skeletal site-specific fractures
}

\author{
Yanshan Wang ${ }^{1 *}+$, Saeed Mehrabi ${ }^{1}$, Sunghwan Sohn ${ }^{1}$, Elizabeth J. Atkinson ${ }^{1}$, Shreyasee Amin ${ }^{2,3}$ \\ and Hongfang Liu ${ }^{1+}$
}

From The Sixth IEEE International Conference on Healthcare Informatics (ICHI 2018)

New York, NY, USA. 4-7 June 2018

\begin{abstract}
Background: Osteoporosis has become an important public health issue. Most of the population, particularly elderly people, are at some degree of risk of osteoporosis-related fractures. Accurate identification and surveillance of patient populations with fractures has a significant impact on reduction of cost of care by preventing future fractures and its corresponding complications.

Methods: In this study, we developed a rule-based natural language processing (NLP) algorithm for identification of twenty skeletal site-specific fractures from radiology reports. The rule-based NLP algorithm was based on regular expressions developed using MedTagger, an NLP tool of the Apache Unstructured Information Management Architecture (UIMA) pipeline to facilitate information extraction from clinical narratives. Radiology notes were retrieved from the Mayo Clinic electronic health records data warehouse. We developed rules for identifying each fracture type according to physicians' knowledge and experience, and refined these rules via verification with physicians. This study was approved by the institutional review board (IRB) for human subject research.

Results: We validated the NLP algorithm using the radiology reports of a community-based cohort at Mayo Clinic with the gold standard constructed by medical experts. The micro-averaged results of sensitivity, specificity, positive predictive value (PPV), negative predictive value (NPV), and F1-score of the proposed NLP algorithm are 0.930, 1.0, 1.0, $0.941,0.961$, respectively. The F1-score is 1.0 for 8 fractures, and above 0.9 for a total of 17 out of 20 fractures (85\%).

Conclusions: The results verified the effectiveness of the proposed rule-based NLP algorithm in automatic identification of osteoporosis-related skeletal site-specific fractures from radiology reports. The NLP algorithm could be utilized to accurately identify the patients with fractures and those who are also at high risk of future fractures due to osteoporosis. Appropriate care interventions to those patients, not only the most at-risk patients but also those with emerging risk, would significantly reduce future fractures.
\end{abstract}

Keywords: Fracture identification, Natural language processing, Radiology reports, Electronic health records

*Correspondence: wang.yanshan@mayo.edu

† Yanshan Wang and Hongfang Liu contributed equally to this work and should be considered co-corresponding authors.

${ }^{1}$ Division of Biomedical Statistics and Informatics, Department of Health Sciences Research, Mayo Clinic, 200 1st ST SW, Rochester, MN, USA

Full list of author information is available at the end of the article

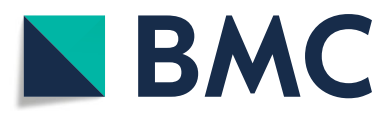

(c) The Author(s). 2019 Open Access This article is distributed under the terms of the Creative Commons Attribution 4.0 International License (http://creativecommons.org/licenses/by/4.0/), which permits unrestricted use, distribution, and reproduction in any medium, provided you give appropriate credit to the original author(s) and the source, provide a link to the Creative Commons license, and indicate if changes were made. The Creative Commons Public Domain Dedication waiver (http://creativecommons.org/publicdomain/zero/1.0/) applies to the data made available in this article, unless otherwise stated. 


\section{Introduction}

Osteoporosis is an important public health issue, owing to the fact that a substantial proportion of the aging population will experience fractures associated with low bone mass [1]. According to World Health Organization (WHO), an estimated 10 million Americans over 50 years old already have osteoporosis [2], while over 33 million more have "osteopenia", which is a reduction in bone density that can precede osteoporosis. The total number with low bone mass could reach 61 million by 2020 [3]. Likewise, the estimated 2 million osteoporosis-related fractures in 2005 could exceed 3 million by 2025, with an associated increase in costs from $\$ 16.9$ billion to $\$ 25.3$ billion annually [4]. It also has been shown that most of the population, besides elderly people, are at some degree of risk of osteoporosis-related fractures [5]. Accurate identification of fractures will help identify the patients with high risk of future fractures. Applying appropriate interventions to those patients would significantly reduce future fracture, and reduce the cost of care [5].

Significant amounts of information for identification of fractures are only available in a narrative format. Manually extracting such information from clinical narratives is time consuming and expensive. Fortunately, prevalence of Electronic Health Records (EHRs) makes automated fracture identification more feasible than before. EHR has provided new means to extract information through analysis of clinical diagnostic narratives. Radiology reports are one particularly rich source of clinical diagnostic information. Researchers have utilized Natural Language Processing (NLP) techniques to extract information from these reports [6]. NLP algorithms have been developed for automatic information extraction for a variety of diseases [7, 8], including appendicitis [9], pneumonia [10], thromboembolic diseases [11], and various potentially malignant lesions [12]. Most of these applications exploit manually designed rules based on medical experts' knowledge and experience, which has been called rule-based NLP algorithms.

A few rule-based NLP algorithms have been proposed for the identification of fractures from radiology reports in the literature. Yadav et al. [13] developed a hybrid system of NLP and machine learning for automated classification of orbital fracture from emergency department computed tomography (CT) reports. Wagholikar et al. [14] used NLP rules to classify limb abnormalities from radiology reports using a clinician informed gazetteer methodology. VanWormer et al. [15] developed a keyword search system to identify patients who were injured because of tree stand falls during hunting seasons. Do et al. [16] used NLP in an application that extracts both the presence of fractures and their anatomic location. Grundmeier et al. [17] implemented and validated NLP tools to identify long bone fractures for pediatric emergency medicine quality improvement. However, few of these studies have welldefined skeletal site-specific fractures, and report specific rules for each of skeletal site-specific fractures from radiology reports.

In this study, we developed a rule-based NLP algorithm for identification of twenty skeletal site-specific fractures from radiology reports. We applied and tested the algorithm on a cohort at Mayo Clinic within a well-defined community, Rochester Epidemiology Project (REP) [18-20], with the gold standard constructed by medical experts.

\section{Method \\ Study setting}

The study was conducted at Mayo Clinic, Rochester MN. A fracture cohort of 1349 Mayo Clinic patients who were 18 years of age or older and experienced fractures in 2009-2011 was utilized in our study [21, 22]. In addition, we selected a control cohort of 2000 Mayo Clinic patients who lived in Olmsted County any time from 2008-2012, were 18 years of age or older in 2008, and had no evidence of having a fracture through their entire known followup in 2008-2017. Nurses with multiple years of experience abstracting fractures reviewed each subject's entire patient record and created the gold standard. This study was approved by the institutional review board (IRB) for human subject research.

We utilized twenty skeletal site-specific fractures that have been used by the Osteoporosis Research Program at Mayo Clinic for over 30 years [21,22]. These skeletal sites included ankle, clavicle, distal forearm, face, feet and toes, hand and figures, patella, pelvis, proximal femur, proximal humerus, ribs, scapula, shaft and distal femur, shaft and distal humerus, shaft and proximal radius/ulna, skull, sternum, tibia and fibula, vertebral body, and other spine. Since a single subject may have experienced multiple fractures, our study included a total of 2356 fractures in 1349 subjects.

Radiology notes, including general radiography reports (such as X-ray reports), computed tomography reports, magnetic resonance imaging reports, nuclear medicine radiology reports, mammography reports, ultrasonography reports, neuroradiology reports, were retrieved from the Mayo Clinic EHR warehouse for all the subjects.

For each fracture type, we randomly utilized $70 \%$ of the subjects in the fracture cohort as training data to develop the rule-based NLP algorithm, and the remaining $30 \%$ of the subjects in the fracture cohort with the identical number of subjects randomly sampled from the control cohort as testing data to evaluate the algorithm. The exact number of the study subjects in the training and testing data for each fracture type is listed in Table 1. 
Table 1 Fractures and the corresponding number of patients in the training and testing data

\begin{tabular}{|c|c|c|c|}
\hline Fractures & $\begin{array}{l}\text { \# Patients in } \\
\text { Training }\end{array}$ & $\begin{array}{l}\text { \# Patients in } \\
\text { Testing }\end{array}$ & Total \\
\hline Ankle & 90 & 76 & 166 \\
\hline Clavicle & 32 & 26 & 58 \\
\hline Distal Forearm & 102 & 86 & 188 \\
\hline Face & 60 & 52 & 112 \\
\hline Feet and Toes & 185 & 158 & 343 \\
\hline Hand and Fingers & 140 & 120 & 260 \\
\hline Other Spine & 28 & 24 & 52 \\
\hline Patella & 10 & 8 & 18 \\
\hline Pelvis & 62 & 52 & 114 \\
\hline Proximal Femur & 74 & 62 & 136 \\
\hline Proximal Humerus & 48 & 40 & 88 \\
\hline Ribs & 104 & 90 & 194 \\
\hline Scapula & 9 & 8 & 17 \\
\hline Shaft and Distal Femur & 13 & 10 & 23 \\
\hline Shaft and Distal Humerus & 13 & 12 & 25 \\
\hline $\begin{array}{l}\text { Shaft and Proximal } \\
\text { Radius/Ulna }\end{array}$ & 41 & 36 & 77 \\
\hline Skull & 4 & 4 & 8 \\
\hline Sternum & 5 & 4 & 9 \\
\hline Tibia and Fibula & 37 & 32 & 69 \\
\hline Vertebral Body & 215 & 184 & 399 \\
\hline
\end{tabular}

\section{The rule-based NLP algorithm}

Figure 1 shows the overall design of the study. The rulebased NLP algorithm was developed using Medtagger, an NLP tool developed based on the Apache Unstructured Information Management Architecture (UIMA) pipeline [23], to facilitate information extraction from clinical narratives. Based on the training data, we developed rules for identifying each fracture type according to physicians' knowledge and experience, and refined these rules via verification with physicians. These rules were also supplemented with historical rules developed by the Osteoporosis Research Program to aid the nurse abstractors in fracture identification.

The regular expressions in our NLP algorithm for each fracture are listed in Table 2 and the fracture modifiers are listed in Table 3. MedTagger uses the rules within detected sentences to identify a specific fracture type. The rules are " $\mid \mathrm{b}(\%$ reFractureModifier).*(\%reFractureCategory) $) \mathrm{b} "$ or "lb(\%reFractureCategory). "(\%reFractureModifier) $\mid \mathrm{b}$ " where reFractureCategory represents regular expressions for the specific fracture category in Table 2 and reFractureModifier modifiers in Table 3. During the interactive refinement of NLP algorithm with physicians, we also added a few exclusion rules to reduce the number of false positives in the training data. For example, if keywords, such as "rule out" or "r/o", and "negative" occurred in the sentence, we excluded the extracted fractures. Finally the rule-based NLP algorithm was evaluated on the held-out testing data.

\section{Evaluation}

We calculated the overall agreement between the proposed NLP algorithm and the gold standard. Five metrics, namely sensitivity, specificity, positive predictive value (PPV), negative predictive value (NPV) and F1-score, were used to measure the performance of the NLP system for each fracture, and micro-averaged values of these metrics were used to evaluate the overall performance. The definitions of these metrics are as follows:

$$
\begin{aligned}
& \text { Sensitivity }=\frac{T P}{T P+F N}, \text { Specificity }=\frac{T N}{T N+F P}, \\
& P P V=\frac{T P}{T P+F P}, N P V=\frac{T N}{T N+F N}, \\
& \text { F1-score }=\frac{2 P P V \cdot \text { Sensitivity }}{P P V+\text { Sensitivity }}, \\
& \text { Sensitivity }_{\text {micro }}=\frac{\sum_{i} T P_{i}}{\sum_{i} T P_{i}+F N_{i}}, \\
& \text { Specificity }_{\text {micro }}=\frac{\sum_{i} T N_{i}}{\sum_{i} T N_{i}+F P_{i}}, \\
& P P V_{\text {micro }}=\frac{\sum_{i} T P_{i}}{\sum_{i} T P_{i}+F P_{i}}, \\
& N P V_{\text {micro }}=\frac{\sum_{i} T N_{i}}{\sum_{i} T N_{i}+F N_{i}}, \\
& \text { F1-score } \text { micro }=\frac{2 P P V_{\text {micro }} \cdot \text { Sensitivity }_{\text {micro }}}{P P V_{\text {micro }}+\text { Sensitivity }_{\text {micro }}},
\end{aligned}
$$

where TP, TN, FP, and FN represent true positives, true negatives, false positives, and false negatives, respectively, and $i=1,2, \ldots, 20$ is the $i$ th fracture type.

\section{Results}

Table 4 shows the experimental results of the NLP algorithm. Overall the NLP algorithm has a high micro-average F1-score of 0.961 , which validates the effectiveness of the proposed NLP algorithm for identifying the twenty skeletal sitespecific fractures from the radiology reports. The microaverage PPV and specificity are 1.0 and 1.0, respectively, which shows that the NLP algorithm has high precision in identifying positives and negatives. The micro-average sensitivity is 0.930 , which implies that the rules in the NLP algorithm are sufficient in identifying fractures. 8 fracture types (40\%) have obtained F1-scores of 1.0 while a total of 17 fracture types (85\%) F1-scores of above 0.9 (including 1.0). The lowest F1-score is to extract vertebral body fractures $(\mathrm{F} 1$-score $=0.806)$.

Here we provide a few examples of false positives and false negatives during training, and analyze why the NLP algorithm failed in these cases. The NLP algorithm was unable to identify ankle fracture for Patient A since the 


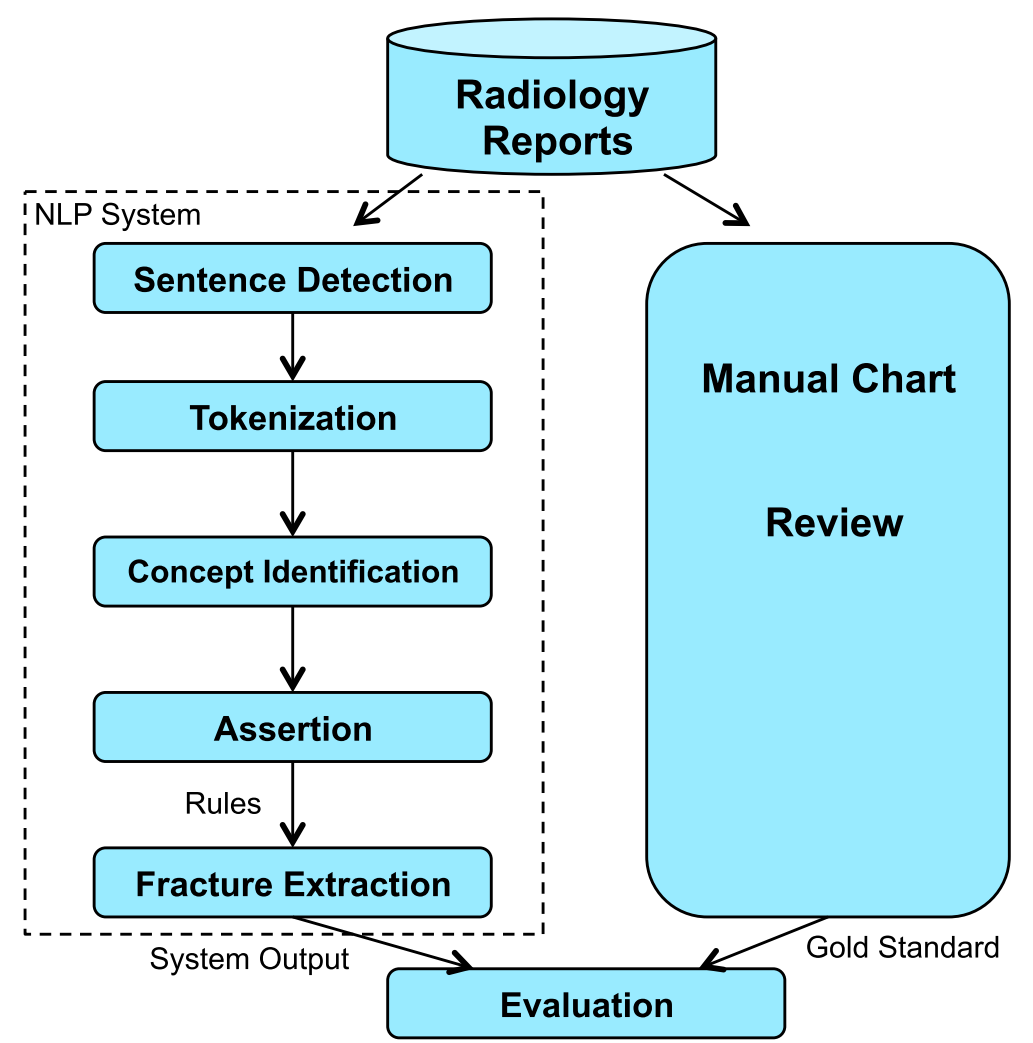

Fig. 1 Study Design

indication term "debride" that rarely appeared in the training data was not considered in the rules. The same situation happened for Patient B who had face fracture but the NLP algorithm failed to identify due to the missing keyword "lamina papyracea" in the rules. Some false positives and false negatives fundamental problems in NLP, such as sentence boundary detection and negation detection. For example, the algorithm failed to detect the sentence starting from "superior" in Patient C's clinical note. The algorithm failed to detect the negation for Patient $\mathbf{D}$. Thus, we added rules for boundary detection and terms for negation that were specific to our clinical note corpus.

Patient A: Exam: Fluoro Assistance less < $1 \mathrm{hr}$ Indications: left ankle debride ORIGINAL REPORT ? DATE Mobile image intensifier used. Electronically signed by: PHYNAME. DATE.

Patient B: CT examination of the head and maxillofacial bones performed without IV contrast demonstrates a mildly displaced fracture of the superior right lamina papyracea.

Patient C: No inflammatory changes to suggest cholecystitis superior endplate compression fractures of T11 and T12 vertebral body

Patient D: The bone scan was negative for an acute fracture at that area, although an acute fracture in the vertebral body of L1 was noted.
Some terms are clinically ambiguous. For example, the term "phalanx" is ambiguous since it could refer to either a finger or a toe. Based on the training data, we added modifiers "proximal/distal/middle" to "phalanx" for hand and fingers fractures. A better solution might be using the metadata of radiology notes to pre-identify whether the $\mathrm{X}$-ray is for hand or foot.

Some false negatives are due to the co-reference in the report. For example, Patient $\mathbf{E}$ was not identified due to that the term "findings" is co-referenced to the hand fractures. Some false negatives are due to the ambiguity or incorrect negation detection. For example, Patient $\mathbf{F}$ had vertebral body fracture based on the meaning of sentence but was incorrectly classified as negated.

Patient E: Cortical irregularity of the dorsal aspect of the distal tuft of the left thumb. Findings likely represent a small fracture.

Patient F: It does not appear the L1 compression fracture is the cause of her pain.

\section{Discussion}

We have developed a rule-based NLP algorithm for the identification of twenty skeletal site-specific fractures from radiology reports. We have validated its effectiveness using the radiology reports of a community-based cohort at Mayo Clinic. The NLP algorithm could be utilized to 
Table 2 Regular Expressions in the rule-based NLP algorithm for the identification of fractures

\begin{tabular}{|c|c|}
\hline Fractures & Regular Expressions \\
\hline Ankle & $\begin{array}{l}\text { (inversion)?ankle |tillaux|bimalleolar |distal.*(fibular|tibial) |dupuytren's |(lateral|medial|posterior) malleolus } \\
\text { |Pott's |trimalleolar }\end{array}$ \\
\hline Clavicle & (shaft|acromial end) of clavicle |interligamentous |collar bone |clavic(le|al) |clav | \\
\hline Distal Forearm & $\begin{array}{l}\text { barton's |colles' |(distal|metaphyseal).*(wrist|radius|radial|ulna|ulnar|forearm) |smith's |styloid process |head } \\
\text { of ulna(r)? |ulna(r)? head |wrist }\end{array}$ \\
\hline Face & $\begin{array}{l}\text { (inferior )?maxilla(ry)? Inasal |(upper|lower)?jaw |orbit(al)? Imalar bone |palate |mandible |zygoma(tic)? } \\
\text { |mandibular( ramus)? |facial |naso-orbital }\end{array}$ \\
\hline Feet and Toes & $\begin{array}{l}\text { (meta)?tarsal |astragalus |instep |calcaneus los calcis |navicular |cuboid |cuneiform |talonavicular ossicle |heel } \\
\text { |talus |phalan(x|ges?) |toe }\end{array}$ \\
\hline Hand and Fingers & $\begin{array}{l}\text { hand |fingers? |(meta)?carpals? Imc |(hand |finger) phalanges |(proximal|distal|middle).."phalanx |capitate } \\
\text { |hamate |lunate |scaphoid |navicular |trapezi(um|id) |pisiform |triquetrum |metacarpus |bennett's |thumb } \\
\text { |sesamoid |boxer's |bar room }\end{array}$ \\
\hline Other Spine Fractures & $\begin{array}{l}\text { vertebra(e||) |cervical vertebrae |posterior elements of vertebrae |coccyx |spinous process |neural arch } \\
\text { |transverse process |spine |pedicle } \mid C(1|2| 3|4| 5 \mid 6)\end{array}$ \\
\hline Patella & knee ?(cap|pan) |patella(r)? \\
\hline Pelvis & $\begin{array}{l}\text { acetabulum |acetabular |pelvic rim |ilium |pubis |pubic |innominate |rami |ischium |ischial |sacrum |sacral } \\
\text { |obturator ring |pelvi(c|s) }\end{array}$ \\
\hline Proximal Femur & $\begin{array}{l}\text { (femoral |femur)(head|neck) |(trans)?cervical |(sub)?capital |intracapsular |trans( |-)?epiphyseal |base of neck } \\
\text { |basilar femoral neck |cervicotrochanteric |(greater|lesser) trochanter |(inter|per|intra)trochanteric }\end{array}$ \\
\hline Proximal Humerus & $\begin{array}{l}\text { (anatomical|surgical)? (head|neck|head(-|/)neck|neck(-|/)head) |(humerus|humeral) (|shoulder|proximal end) } \\
\text { |extra ?capsular |(humerus|humeral).*(head|neck|head(-|/)neck|neck(-|/)head) |head of (humerus|humeral) } \\
\text { |(greater|lesser)? tuberosity |proximal humerus |humerus proximal }\end{array}$ \\
\hline Ribs & rib(s)? |(rib|thoracic) cage \\
\hline Scapula & acromion|coracoid( process)? |scapula |glenoid( cavity|fossa)? |shoulder blade \\
\hline Shaft and Distal Femur & $\begin{array}{l}\text { diaphyseal fracture of femur |subtrochanteric |(lateral|medial) condylar |supracondylar |(shaft|lower end) of } \\
\text { femur |mid femur }\end{array}$ \\
\hline Shaft and Distal Humerus & $\begin{array}{l}\text { elbow |condylar |shaft of (humerus|humeral) |(distal|end of|shaft).*(humerus|humeral) |supracondylar |epi- } \\
\text { condyle }\end{array}$ \\
\hline Shaft and Proximal Radius/Ulna & $\begin{array}{l}\text { proximal.*(forearm|radius|radial|ulna(r)?) |coronoid process |metaphyseal of (the )?proxi- } \\
\text { mal.*(forearm|radius|radial|ulna(r)?) |(radius|ulna) diaphyseal |Monteggia('s)? |Dupuytren('s)? } \\
\mid(\text { neck|head|head(-|/)neck|neck(-|/)head) of.*(radius|radial) |(radius|radial) (neck|head|head(-|//)neck|neck(- } \\
\mid / / \text { head) |Galeazzi('s)? |shaft (of)? (ulna(r)? |radius)|radial shalf |ulna(r)? shaft |metadiaphyseal |olecranon( } \\
\text { process)? }\end{array}$ \\
\hline Skull & $\begin{array}{l}\text { (base|vault) of the skull |vault |(ethmoid|sphenoid) (sinus|base) |sphenoid |occipital |vertex skull |calvaria(I)? } \\
\text { |calvarium }\end{array}$ \\
\hline Sternum & breast()?bone |sternum |manubrium |xyphoid \\
\hline Tibia and Fibula & $\begin{array}{l}\text { (proximal )?fibula |intercondylar eminence shaft |(lateral||tibia |fibula) condyle |lateral tibial plateau |((medial } \\
\text { )?tibia |tibial) shaft |tuberosity }\end{array}$ \\
\hline Vertebral Body & $\begin{array}{l}\text { ballooning (of inter ?spaces?)? |biconcave |burst |axis |cod-fish |endplate |loss of height ||(t||)-?spine |lumbar } \\
\text { |thoracic |collapse ||(1|2|3|4|5)|t(1|2|3|4|5|6|7|8|9|10|11) }\end{array}$ \\
\hline
\end{tabular}

accurately identify the patients with fractures and those who are also at high risk of future fractures due to osteoporosis. Appropriate care interventions to those patients, not only the most at-risk patients but also those with emerging risk, would significantly reduce future fracture. This would particularly help transition the current form of fee-for-service care to value-based care since it might be difficult to make impactful interventions for the real high- risk category of patients while more significant to focus on the emerging-risk category in an attempt to keep them from becoming high risk [24].

Recently, machine learning techniques have shown promise for automated outcome classification, particularly when large volumes of data are available [8]. Since the rules in the NLP algorithm need to be laboriously fine-designed through interactive verifications between

Table 3 Fracture modifiers 
Table 4 Experimental results of the NLP algorithm for each fracture type

\begin{tabular}{|c|c|c|c|c|c|}
\hline Fractures & Sensitivity & Specificity & PPV & NPV & F1-score \\
\hline Ankle & 0.974 & 1.000 & 1.000 & 0.974 & 0.987 \\
\hline Clavicle & 1.000 & 1.000 & 1.000 & 1.000 & 1.000 \\
\hline Distal Forearm & 1.000 & 1.000 & 1.000 & 1.000 & 1.000 \\
\hline Face & 0.760 & 1.000 & 1.000 & 0.806 & 0.864 \\
\hline Feet and Toes & 0.960 & 1.000 & 1.000 & 0.962 & 0.980 \\
\hline Hand and Fingers & 0.918 & 1.000 & 1.000 & 0.924 & 0.957 \\
\hline $\begin{array}{l}\text { Other Spine } \\
\text { Fractures }\end{array}$ & 0.875 & 1.000 & 1.000 & 0.889 & 0.933 \\
\hline Patella & 1.000 & 1.000 & 1.000 & 1.000 & 1.000 \\
\hline Pelvis & 0.952 & 1.000 & 1.000 & 0.955 & 0.976 \\
\hline Proximal Femur & 1.000 & 1.000 & 1.000 & 1.000 & 1.000 \\
\hline $\begin{array}{l}\text { Proximal } \\
\text { Humerus }\end{array}$ & 1.000 & 1.000 & 1.000 & 1.000 & 1.000 \\
\hline Ribs & 0.933 & 1.000 & 1.000 & 0.938 & 0.966 \\
\hline Scapula & 1.000 & 1.000 & 1.000 & 1.000 & 1.000 \\
\hline $\begin{array}{l}\text { Shaft and Distal } \\
\text { Femur }\end{array}$ & 0.800 & 1.000 & 1.000 & 0.833 & 0.889 \\
\hline $\begin{array}{l}\text { Shaft and Distal } \\
\text { Humerus }\end{array}$ & 0.857 & 1.000 & 1.000 & 0.875 & 0.923 \\
\hline $\begin{array}{l}\text { Shaft and } \\
\text { Proximal } \\
\text { Radius/Ulna }\end{array}$ & 0.952 & 1.000 & 1.000 & 0.955 & 0.976 \\
\hline Skull & 1.000 & 1.000 & 1.000 & 1.000 & 1.000 \\
\hline Sternum & 1.000 & 1.000 & 1.000 & 1.000 & 1.000 \\
\hline Tibia and Fibula & 0.944 & 1.000 & 1.000 & 0.947 & 0.971 \\
\hline Vertebral Body & 0.675 & 1.000 & 1.000 & 0.755 & 0.806 \\
\hline Micro-Average & 0.930 & 1.000 & 1.000 & 0.941 & 0.961 \\
\hline
\end{tabular}

rule designers and physicians, machine learning provides a solution that significantly reduces or eliminates the workload of designing rules. One of our ongoing works is to apply machine learning classifiers and advanced deep learning methods to tackle the fracture classification task $[8,25]$. However, the rule-based NLP algorithm is straightforward to interpret for physicians and easy to be modified through interactive refinement with physicians' feedbacks. As shown by [6], only one-third of the vendors relied entirely on machine learning, and the systems developed by large vendors, such as IBM, SAP, and Microsoft, are completely rule-based. An additional benefit we observed was that the NLP algorithm augmented the guideline for manually annotating fractures as many keywords from the algorithm had been added in the guideline. For example, "clav fx" has been added to the guideline of abstracting clavicle fracture; "inferior maxillary", "zygomatic", "facial" and "naso-orbital" have been added for face fracture; "C1"-"C6" have been added for other spine fractures; and "acetabular", "sacral", "ischial", "pubic" have been added for pelvis fracture.

This study has two limitations. First, we only verified the effectiveness of NLP algorithm on radiology reports. It would be interesting to evaluate the NLP algorithm on other free-text EHR resources, such as clinical notes. Second, we only tested the NLP algorithm in one institution. It is also interesting to study the portability of the NLP algorithm across institutions with disparate sublanguages [26].

\section{Conclusions}

In this study, we developed a rule-based NLP algorithm for identification of twenty skeletal site-specific fractures from radiology reports. The keywords and regular expressions in the comprehensive NLP algorithm could be reused in different fracture identification applications. Our empirical experiments validated the effectiveness of the NLP algorithm using the radiology reports of a community-based cohort at Mayo Clinic. The microaveraged results of the NLP algorithm for the twenty fractures are $0.930,1.0,1.0,0.941,0.961$ in terms of sensitivity, specificity, PPV, NPV, and F1-score, respectively. 8 fracture types (40\%) have obtained F1-scores of 1.0 while a total of 17 fracture types (85\%) F1-scores of above 0.9 . The results verified the effectiveness of the proposed rule-based NLP algorithm in automatic identification of fractures from radiology reports.

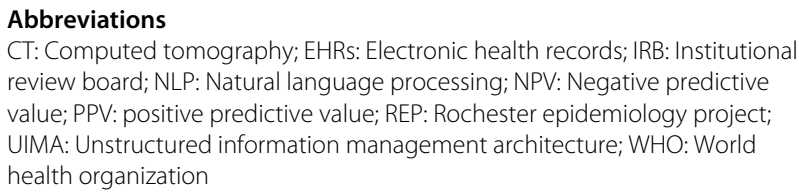
review board; NLP: Natural language processing; NPV: Negative predictive value; PPV: positive predictive value; REP: Rochester epidemiology project; UIMA: Unstructured information management architecture; WHO: World health organization

\section{Acknowledgements}

The authors would like to thank Marcia Erickson, R.N., Julie Gingras, R.N. and Joan LaPlante, R.N. for assistance with the fracture validation. The view(s) expressed herein are those of the author(s) and do not reflect the official policy or position of Mayo Clinic, or the National Institute of Health $(\mathrm{NIH})$.

\section{Funding}

This work and publication costs are funded by National Institute of Health (NIH) research grants R01LM011934, R01EB19403, R01LM11829, PO1AG04875 and U01TR02062. This work was made possible by the Rochester Epidemiology Project (NIH R01AG034676), U.S. Public Health Service.

\section{Availability of data and materials}

The EHR dataset referenced in this paper comes from Mayo Clinic, which are not publicly available due to the privacy of patients.

\section{About this supplement}

This article has been published as part of BMC Medical Informatics and Decision Making Volume 19 Supplement 3, 2019: Selected articles from the first International Workshop on Health Natural Language Processing (HealthNLP 2018). The full contents of the supplement are available online at https://

bmcmedinformdecismak.biomedcentral.com/articles/supplements/volume19-supplement-3.

\section{Ethics approval and consent to participate}

The EHR dataset was acquired through Mayo Clinic EHR system, and were performed under an Institutional Review Board protocol reviewed and approved by Mayo Clinic. 


\section{Authors' contributions}

YW: conceptualized, designed, and wrote the study. SM: analyzed the data; edited the manuscript. SS: edited the manuscript. EA: analyzed the data; edited the manuscript. SA: analyzed the data; edited the manuscript. HL: conceptualized, and edited the manuscript. All authors read and approved the final manuscript.

\section{Consent for publication}

Not applicable.

\section{Competing interests}

The authors declare that they have no competing interests.

\section{Author details}

${ }^{1}$ Division of Biomedical Statistics and Informatics, Department of Health Sciences Research, Mayo Clinic, 200 1st ST SW, Rochester, MN, USA. ²Division of Rheumatology, Department of Medicine, Mayo Clinic, 200 1st ST SW, MN, Rochester, USA. ${ }^{3}$ Division of Epidemiology, Department of Health Sciences Research, Mayo Clinic, 200 1st ST SW, MN, Rochester, USA.

\section{Published: 4 April 2019}

\section{References}

1. Melton LJ. Adverse outcomes of osteoporotic fractures in the general population. J Bone Miner Res. 2003;18(6):1139-41.

2. Kanis JA, Melton LJ, Christiansen C, Johnston CC, Khaltaev N. The diagnosis of osteoporosis. J Bone Miner Res. 1994;9(8):1137-41.

3. Khosla S, Bellido TM, Drezner MK, Gordon CM, Harris TB, Kiel DP, Kream BE, LeBoff MS, Lian JB, Peterson CA, et al. Forum on aging and skeletal health: summary of the proceedings of an asbmr workshop. J Bone Miner Res. 2011;26(11):2565-78.

4. Burge R, Dawson-Hughes B, Solomon DH, Wong JB, King A, Tosteson A. Incidence and economic burden of osteoporosis-related fractures in the united states, 2005-2025. J Bone Miner Res. 2007;22(3):465-75.

5. Ettinger B, Black D, Dawson-Hughes B, Pressman A, Melton L. Updated fracture incidence rates for the us version of frax ${ }^{\oplus}$. Osteoporos Int. 2010;21(1):25-33

6. Wang Y, Wang L, Rastegar-Mojarad M, Moon S, Shen F, Afzal N, Liu S, Zeng Y, Mehrabi S, Sohn S, Liu H. Clinical information extraction applications: a literature review. J Biomed Inform. 2018;77:34-49.

7. Pons $E$, Braun $L M$, Hunink MM, Kors JA. Natural language processing in radiology: a systematic review. Radiology. 2016;279(2):329-43.

8. Wang Y, Sohn S, Liu S, Shen F, Wang L, Atkinson EJ, Amin S, Liu H. A clinical text classification paradigm using weak supervision and deep representation. BMC Med Inform Decis Mak. 2019;19(1):1.

9. Rink B, Roberts K, Harabagiu S, Scheuermann RH, Toomay S, Browning T, Bosler T, Peshock R. Extracting actionable findings of appendicitis from radiology reports using natural language processing. AMIA Summits Transl Sci Proc. 2013;2013:221.

10. Chapman WW, Fizman M, Chapman BE, Haug PJ. A comparison of classification algorithms to automatically identify chest $x$-ray reports that support pneumonia. J Biomed Inform. 2001;34(1):4-14.

11. Pham A-D, Névéol A, Lavergne $T$, Yasunaga $D$, Clément $O$, Meyer $G$, Morello R, Burgun A. Natural language processing of radiology reports for the detection of thromboembolic diseases and clinically relevant incidental findings. BMC Bioinformatics. 2014;15(1):266.

12. Garla V, Taylor C, Brandt C. Semi-supervised clinical text classification with laplacian svms: an application to cancer case management. J Biomed Inform. 2013;46(5):869-75.

13. Yadav K, Sarioglu E, Smith M, Choi H-A. Automated outcome classification of emergency department computed tomography imaging reports. Acad Emerg Med. 2013;20(8):848-54.

14. Wagholikar A, Zuccon G, Nguyen A, Chu K, Martin S, Lai K, Greenslade J. Automated classification of limb fractures from free-text radiology reports using a clinician-informed gazetteer methodology. Australas Med J. 2013;6(5):301.

15. VanWormer JJ, Holsman RH, Petchenik JB, Dhuey BJ, Keifer MC Epidemiologic trends in medically-attended tree stand fall injuries among wisconsin deer hunters. Injury. 2016;47(1):220-5.
16. Do BH, Wu AS, Maley J, Biswal S. Automatic retrieval of bone fracture knowledge using natural language processing. J Digit Imaging. 2013;26(4):709-13.

17. Grundmeier RW, Masino AJ, Casper TC, Dean JM, Bell J, Enriquez R, Deakyne S, Chamberlain JM, Alpern ER, Network PECAR, et al. Identification of long bone fractures in radiology reports using natural language processing to support healthcare quality improvement. Appl Clin Inform. 2016;7(04):1051-68.

18. Rocca WA, Yawn BP, Sauver JLS, Grossardt BR, Melton LJ. History of the Rochester Epidemiology Project: half a century of medical records linkage in a US population. In: Mayo Clinic proceedings, vol. 87, No. 12. Elsevier; 2012. p. 1202-13.

19. St Sauver JL, Grossardt BR, Yawn BP, Melton III LJ, Pankratz JJ, Brue SM, Rocca WA. Data resource profile: the rochester epidemiology project (rep) medical records-linkage system. Int J Epidemiol. 2012;41 (6):1614-24.

20. St. Sauver JL, Grossardt BR, Yawn BP, Melton III LJ, Rocca WA. Use of a medical records linkage system to enumerate a dynamic population over time: the rochester epidemiology project. Am J Epidemiol. 2011;173(9): 1059-68.

21. Amin S, Achenbach SJ, Atkinson EJ, Khosla S, Melton LJ. Trends in fracture incidence: A population-based study over 20 years. J Bone Miner Res. 2014;29(3):581-9.

22. Farr JN, Melton III $\amalg$, Achenbach SJ, Atkinson EJ, Khosla S, Amin S. Fracture Incidence and Characteristics in Young Adults Aged 18 to 49 Years: A Population??? Based Study. J Bone Miner Res. 2017;32(12): 2347-2354.

23. Liu H, Bielinski SJ, Sohn S, Murphy S, Wagholikar KB, Jonnalagadda SR, Ravikumar K, Wu ST, Kullo IJ, Chute CG. An information extraction framework for cohort identification using electronic health records. AMIA Summits Transl Sci Proc. 2013;2013:149.

24. Burwell SM. Setting value-based payment goals?hhs efforts to improve us health care. N Engl J Med. 2015;372(10):897-9.

25. Wang Y, Liu S, Afzal N, Rastegar-Mojarad M, Wang L, Shen F, Kingsbury P, Liu H. A comparison of word embeddings for the biomedical natural language processing. J Biomed Inform. 2018;87:12-20.

26. Sohn S, Wang Y, Wi Cl, Krusemark EA, Ryu E, Ali MH, Juhn YJ, Liu H. Clinical documentation variations and NLP system portability: a case study in asthma birth cohorts across institutions. J Am Med Inform Assoc. 2017;25(3):353-359.

Ready to submit your research? Choose BMC and benefit from:

- fast, convenient online submission

- thorough peer review by experienced researchers in your field

- rapid publication on acceptance

- support for research data, including large and complex data types

- gold Open Access which fosters wider collaboration and increased citations

- maximum visibility for your research: over $100 \mathrm{M}$ website views per year

At BMC, research is always in progress.

Learn more biomedcentral.com/submissions 